\title{
The Relationship between the Use of Social Networking Sites and Sexually Explicit Material, the Internalization of Appearance Ideals and Body Self- Surveillance: Results from a Longitudinal Study of Male Adolescents
}

Sevic, Sandra; Ciprić, Ana; Buško, Vesna; Štulhofer, Aleksandar

Source / Izvornik: Journal of Youth and Adolescence, 2019, -

Journal article, Accepted version

Rad u časopisu, Završna verzija rukopisa prihvaćena za objavljivanje (postprint)

https://doi.org/10.1007/s10964-019-01172-2

Permanent link / Trajna poveznica: https://urn.nsk.hr/urn:nbn:hr:131:508986

Rights / Prava: In copyright/Zaštićeno autorskim pravom.

Download date / Datum preuzimanja: 2023-04-26

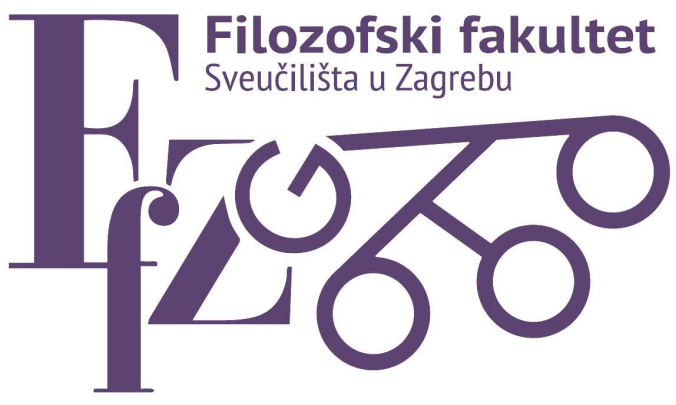

Repository / Repozitorij:

ODRAZ - open repository of the University of Zagreb Faculty of Humanities and Social Sciences
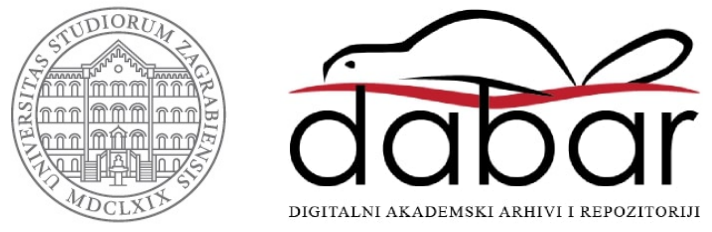
The Relationship between the Use of Social Networking Sites and Sexually Explicit Material, the Internalization of Appearance Ideals and Body Self-Surveillance: Results from a Longitudinal Study of Male Adolescents

Sandra Sevic ${ }^{\mathrm{a}}$

Ana Ciprićb

Vesna Buško ${ }^{\mathrm{c}}$

Aleksandar Štulhofer ${ }^{\mathrm{a}}$

${ }^{\mathrm{a} D e p a r t m e n t ~ o f ~ S o c i o l o g y, ~ F a c u l t y ~ o f ~ H u m a n i t i e s ~ a n d ~ S o c i a l ~ S c i e n c e s, ~ U n i v e r s i t y ~ o f ~ Z a g r e b, ~}$ Croatia; ${ }^{b}$ Department of Public Health, Faculty of Health and Medical Sciences, University of Copenhagen, Denmark; ${ }^{c}$ Department of Psychology, Faculty of Humanities and Social Sciences, University of Zagreb, Croatia

\section{Author Contact Information}

\section{Address for Correspondence:}

Sandra Sevic

Dept. of Sociology

Faculty of Humanities and Social Sciences

University of Zagreb

Ivana Lučića 3, 10000 Zagreb, Croatia

E-mail: s.sevic@gmail.com; fax: +385 1 4092007; phone: +385 14092007 
Ana Ciprić

Dept. of Public Health

Faculty of Health and Medical Sciences

University of Copenhagen

Øster Farimagsgade 5B, 1014 København K, Copenhagen, Denmark E-mail:

anci@sund.ku.dk; phone: +4535326380

Vesna Buško

Dept. of Psychology

Faculty of Humanities and Social Sciences

University of Zagreb

Ivana Lučića 3, 10000 Zagreb, Croatia

E-mail: vesna.busko@ffzg.hr; phone: +385 14092192

Aleksandar Štulhofer

Dept. of Sociology

Faculty of Humanities and Social Sciences

University of Zagreb

Ivana Lučića 3, 10000 Zagreb, Croatia

E-mail: astulhof@ffzg.hr; fax: +385 1 4092007; phone: +385 14092007

Running Head: Pornography use and body surveillance in male adolescents 


\title{
The Relationship between the Use of Social Networking Sites and Sexually Explicit Material, the Internalization of Appearance Ideals and Body Self-Surveillance: Results from a Longitudinal Study of Male Adolescents
}

\begin{abstract}
Although there is now a substantial body of research suggesting a positive association between the exposure to sexualized content in the media and self-objectification/body surveillance, most of the studies have been cross-sectional, conducted in exclusively female samples, focused on the use of traditional media (e.g., printed magazines and TV), and have not assessed the role of the internalization of appearance ideals, which is potentially an important intervening variable in the relationship between media exposure and outcomes related to body concerns. Addressing the need for further assessments of self-objectification in more diverse samples, this study used five-wave longitudinal data to investigate the parallel changes in the use of social networking sites and sexually explicit material and the internalization of appearance ideals and body surveillance in Croatian adolescent men $\left(M_{\text {age at }}\right.$ baseline $=15.9, \mathrm{SD}=.54 ; n=743)$. Over a period of 22 months during the transition from middle to late adolescence, both the internalization of appearance ideals and body surveillance decreased. Furthermore, although the internalization of appearance ideals and body surveillance were associated both at baseline and over time, this study's results did not indicate a longitudinal relationship between respectively the use of online social networking sites and sexually explicit material and either the internalization of appearance ideals or body surveillance among adolescent males. Overall, this study's findings highlight the potential for a more specific assessment of the role of the use of social networking sites and sexually explicit material in self-objectification and body surveillance among young men. Future research may benefit from exploring the relationship between young men's modes of
\end{abstract}


engagement with and motives for the use of social networking sites and body surveillance, as well as the possible association between the use of sexually explicit material and competencybased self-objectification, in particular sexual body functionality.

Key words: Social networking sites; Sexually explicit material; Internalization of appearance ideals; Adolescent men; Objectification theory; Body surveillance; Longitudinal design 


\section{Introduction}

As sexualized portrayals of women and men are becoming more common in today's media, so is a concern that the focus on appearance and being sexy that these images promote encourages not only sexual objectification of others but also self-objectification (Fasoli, Durante, Mari, Zogmaister, \& Volpato, 2018). In other words, seeing other people portrayed as sexual objects in the media may over time lead to perceiving both others and one's self as objects to be viewed and desired, whose value is primarily determined by physical appeal and beauty. Given that self-objectification refers to the prioritization of physical appearance, it is expressed through overly thinking about and monitoring one's body, which is a process termed body surveillance (Fredrickson \& Roberts, 1997). Moradi and Huang (2008) have suggested that an important intervening variable in the link between the experiences of sexual objectification and self-objectification is the internalization of the cultural standards of appearance, so that experiences of sexual objectification may result in body surveillance either due to or through assessing if and to what extent one's body conforms to the societal beauty ideal. Although a substantial body of research suggests a positive association between the exposure to sexualized content in the media and self-objectification/body surveillance, only a few studies conducted so far have extended prior research to online social networking sites and sexually explicit material, whose use is becoming increasingly prevalent in adolescent populations. Therefore, using five-wave longitudinal data that encompass a period of 22 months during the transition from middle to late adolescence, this study explores the links between the use of social networking sites and sexually explicit material, the internalization of appearance ideals, and body surveillance, considering them to be processes that develop and change over time.

\section{Objectification Theory and Gender}


Objectification theory suggests that exposure to sexualized content in the media may over time lead to the internalization of the observer's perspective on the physical self (Fredrickson \& Roberts, 1997). This process, termed self-objectification, refers to viewing oneself through another's eyes and therefore prioritizing physical appearance over other personal qualities. Originally, Fredrickson and Roberts linked objectification theory with the sexualization of women in the media, arguing that the media's focus on body, appearance and physical beauty may negatively impact women's perception of themselves and thus lead to poorer health- and wellbeing-related outcomes, such as body shame, depression, and disordered eating (Fredrickson \& Roberts, 1997; Ward, 2016). Given that girls and women indeed more often than boys and men experience appearance-based evaluations and report higher levels of self-objectification and the related body-objectifying symptoms, such as disordered eating (Calogero, 2009), it is not surprising that as many as two-thirds of the studies using the objectification theory framework have been carried out in exclusively female samples (Karsay, Knoll, \& Matthes, 2018). However, boys and men may also be affected by the media's representations of male bodies. Suggesting that there are pressures on boys and men to achieve the societal body appearance standard, a recent increase in body image concerns and unhealthy appearance modification behaviors has led researchers to more thoroughly explore the role of self-objectification in male health and wellbeing (McCabe \& Ricciardelli, 2004).

\section{Body Surveillance and Wellbeing}

At the cognitive and behavioral levels, self-objectification is manifested as body surveillance. Although both of these concepts include the prioritization of body appearance, self-objectification is conceptualized as the level of importance given to appearance-based attributes in one's self-evaluation, whereas body-surveillance refers to the preoccupation with (cognitive outcome of self-objectification) and habitual monitoring (behavioral outcome of 
self-objectification) of one's physical appearance (Aubrey, 2006; Miner-Rubino, Twenge, \& Fredrickson, 2002). In studies conducted among men, body surveillance has been directly and positively linked with body shame (e.g., Davids, Watson, \& Gere, 2018). However, the evidence is not as straightforward with regard to other related outcomes, such as disordered eating and depression. For example, when controlling for body shame, some studies reported no support for an association between body surveillance and disordered eating behaviors (e.g., Jackson, Zheng, \& Chen, 2016). Similarly, studies that tested more complex models found that body shame mediated the relationship between body surveillance and disordered eating (Engeln-Maddox, Miller, \& Doyle, 2011) or depression (Chen \& Russo, 2010). Although seemingly inconsistent, these findings correspond to objectification theory, which refers specifically to the internalization of the observer's perspective on the self and viewing one's physical self through another's eyes. Therefore, self-objectification lacks the evaluative component and proposes that persons who engage in body surveillance are concerned about their body's appearance above other attributes, be they satisfied or dissatisfied with what they see (Miner-Rubino et al., 2002).

\section{Objectification Theory and Social Networking Sites}

Social networking sites are online media platforms which allow users to create their private or public profiles, post content, and interact with other users of the website, such as their peers or businesses and celebrities, through likes, shares and comments (Holland \& Tiggemann, 2016). Although social networking sites are not sexual in nature and in fact, as per community guidelines, nudity and posting of "adult content" is explicitly restricted (e.g., Facebook, 2019), social networking sites do serve as a platform for conveying appearancerelated and sexualized messages (Karsay et al., 2018) that when internalized may trigger body-related concerns in adolescents. Furthermore, individuals engage with social networking sites not only through passive consumption but also through active content production. 
Providing content such as pictures of one's face or body on social networking sites with the aim of acquiring validation through likes and comments is self-objectifying behavior, as it encourages individuals to consider and present themselves to be viewed and judged by others (Salomon \& Brown, 2019).

Previous research did suggest a link between the use of social networking sites and self-objectification, body image concerns, and disordered eating, but most of the studies conducted so far have used a correlational design and majority female samples, with the focus predominantly being on aspects of body satisfaction and not necessarily on the components of self-objectification (Holland \& Tiggemann, 2016; Karsay et al., 2018). Although related, body satisfaction and self-objectification are different concepts, since self-objectification lacks the evaluative component that is central to the definition of body satisfaction. There seems to be only four studies conducted so far that assessed the relationship between the use of social networking sites and body surveillance in young men, among which two used a longitudinal design and only one included the internalization of appearance ideals. While cross-sectional studies reported a positive relationship between the frequency of use of social networking sites and body surveillance (Manago, Ward, Lemm, Reed, \& Seabrook, 2015; Salomon \& Brown, 2019), one longitudinal study reported a relationship between the initial levels of the use of social networking sites, although not change in use over time, to be related to body surveillance 18 months later (Doornwaard et al., 2014), while the other one found no support for a relationship between the internalization of appearance ideals, frequency of use of social networking sites, and body surveillance in their sample of adolescent men (Vandenbosch \& Eggermont, 2016).

\section{Objectification Theory and Sexually Explicit Material}

The rise in availability and accessibility of sexually explicit material or pornography and research suggesting that many adolescents use sexually explicit material (Koletić, 2017) 
have provoked an increased public and scholarly interest in the effects of the use of sexually explicit material on adolescent development (Peter \& Valkenburg, 2016). Sexually explicit material has been shown to influence the processes of adolescent sexual socialization (Štulhofer, Šoh, Jelaska, Baćak, \& Landripet, 2011) and, pointing to the developmental significance of adolescence, patterns regarding desirable physical features, gendered behaviors, and sexual performance learned and adopted from sexually explicit material during this period (Štulhofer et al., 2011) may persist well into adulthood. As media content that is often appearance-oriented and overtly sexually objectifying (Fritz \& Paul, 2017), exposure to sexually explicit material may contribute to the development of self-objectification and therefore increase the risk of body surveillance among both women and men. As it was suggested in qualitative explorations (Attwood, 2005; Cook, 2006), men are also depersonalized and objectified in pornographic content, where they are portrayed as pleasuregiving instruments, with the focus directed at muscularity, penis size, and stamina.

While several studies have confirmed the negative relationship between the use of sexually explicit material and different aspects of body satisfaction (Peter \& Valkenburg, 2014; Tylka, 2015), one study reported that the relationship between the use of sexually explicit material and a better body image was fully mediated by perceived realism of sexually explicit material (Vogels, 2018). However, only as few as three studies have quantitatively assessed the relationship between the exposure/use of sexually explicit material and body surveillance/monitoring in samples of adolescent and young adult men. Specifically, one cross-sectional study conducted among US male undergraduate students reported a positive relationship between the use of sexually explicit material and body monitoring (Tylka, 2015), while another one, carried out among Belgian male adolescents, found that the relationship between the exposure/use of sexually explicit material and body surveillance was fully, albeit weakly, mediated by the internalization of appearance ideals and self-objectification 
(Vandenbosch \& Eggermont, 2013). Finally, a four-wave longitudinal study using a sample of Dutch adolescents reported that higher initial levels of the use of sexually explicit material, but not change in use over time, predicted more body surveillance 18 months later (Doornwaard et al., 2014).

\section{Objectification Theory and the Internalization of Appearance Ideals}

Moradi and Huang (2008) hypothesized that media use affects self-objectification either due to or through the internalization of appearance ideals. However, in the current research literature there is mixed evidence for the mediation effect of the internalization of appearance ideals (Karsay et al., 2018), in particular with regard to the use of social networking sites. For example, although a recent longitudinal study confirmed that the internalization of appearance ideals mediated the relationship between the exposure to sexualizing content in the traditional media (e.g., printed magazines and TV) and body surveillance, it found no support for a relationship between the internalization of appearance ideals and subsequent frequency of the use of social networking sites and body surveillance (Vandenbosch \& Eggermont, 2016). Furthermore, two recent longitudinal studies even reported unexpected relationships between the key constructs, i.e., body surveillance predicted the internalization of appearance ideals (Vangeel, Vandenbosch, \& Eggermont, 2018 ) or it was negatively associated with media internalization at second measurement (Rousseau \& Eggermont, 2018). Finally, while the media do promote unrealistic and often unattainable appearance standards, the awareness and internalization of these images not only seem to first emerge much earlier than middle adolescence, but along with the media, appearance ideals and their internalization are also shaped by parental and peer influences (McCabe \& Ricciardelli, 2004; Smolak, 2004). Adding to that the fact that the internalization of appearance ideals and body surveillance can and do change over time (Karazsia et al., 2013; Moradi \& Huang, 2008), by middle to late adolescence more so than sequentially, it is 
more likely that media use - and particularly the use of social networking sites (Perloff, 2014)

- the internalization of appearance ideals and body surveillance could be seen as mutually enforcing parallel processes. For these reasons, instead of assessing the relationships between the key constructs in a sequential order, the current study considers whether the initial levels and change over time in the use of social networking sites and sexually explicit material are associated with the initial levels and change over time in the internalization of appearance ideals and body surveillance in adolescent men.

\section{Current Study}

There is theoretical and empirical literature that asserts that body surveillance is triggered either due to or through assessing if and to what extent one's body conforms to the cultural standards of beauty. Therefore, the first hypothesis is that baseline levels and subsequent change in the internalization of appearance ideals will be positively related to baseline levels and subsequent change in male adolescents' body surveillance (Hypothesis 1).

The second hypothesis draws on previous research on the use of social networking sites and sexually explicit material and body surveillance (Doornwaard et al., 2014; Vandenbosch \& Eggermont, 2013) and states that the initial levels of the use of social networking sites and sexually explicit material will be positively associated with the initial levels of the internalization of appearance ideals and body surveillance in male adolescents (Hypothesis 2). Considering that the use of social networking sites includes both consumption and production of objectifying content, the third hypothesis is that compared to the use of sexually explicit material, the use of social networking sites will be characterized by stronger links to the internalization of appearance ideals and body surveillance (Hypothesis 3 ).

Given that theory does suggest that exposure to sexualized content in the media leads to both the internalization of appearance ideals and body surveillance (Fredrickson \& Roberts, 1997; Moradi \& Huang, 2008), and if these processes can change over time (Karazsia et al., 
2013; Moradi \& Huang, 2008), it can be assumed that they would change interdependently.

However, contrary to theory, the only available study that did assess the relationship between the change in the use of social networking sites and sexually explicit material over time and body surveillance found no support for the relationship between the change in media use and body surveillance at the end of the study period (Doornwaard et al., 2014). Therefore, expanding on the findings reported by Doornwaard et al. (2014), in addition to body surveillance, the analytical models tested in this study also include the internalization of appearance ideals in order to answer the following research question: Is change over time in the use of social networking sites and sexually explicit material positively related to changes in the internalization of appearance ideals and body surveillance?

Finally, based on the literature that suggested an important role of peer (Rousseau, Eggermont, \& Frison, 2017; Vandenbosch \& Eggermont, 2016) and family relationships (Bearman, Presnell, Martinez, \& Stice, 2006; de Vries, Vossen, \& van der Kolk - van der Boom, 2019) in the association between media use and body-related concerns in adolescents, peer- and family-level indicators were included in the statistical model as potential confounders of the observed associations between the four constructs of interest.

\section{Methods}

\section{Participants}

Data for the present study were collected as part of a larger longitudinal research project that focused on the use of sexualized media among Croatian adolescents (PROBIOPS; Prospective Biopsychosocial Study of the Effects of Sexually Explicit Material on Young People's Sexual Socialization and Health). Croatia is a Southeast European country that became a Member State of the European Union in 2013. Although a trend of increasing religiosity (Croatia is predominantly Roman Catholic and one of the most religious countries in the European Union; Luijkx, Halman, Sieben, Brislinger, \& Quandt, 2017) has been 
observed in the past two decades, including among young people (Marinović Jerolimov \& Jokić, 2010), Croatian adolescents are characterized by relative sexual permissiveness and gender role egalitarianism, particularly in urban areas (Marinović Jerolimov \& Ančić, 2014).

The panel sample included students from 14 of the total of 22 secondary schools in the third largest Croatian city, Rijeka; due to financial limitations, seven small schools were omitted from the sample, while one larger school was omitted due to a pending investigation for arson. At baseline (December 2015), the panel included 1,287 participants $\left(M_{\mathrm{age}}=15.8\right.$, $\mathrm{SD}=.52$ ) or $78 \%$ of the city's high school sophomore population.

Panel attrition $\left(\mathrm{T} 1_{\text {December } 2015}=1,287, \mathrm{~T} 2_{\text {April } 2016}=1,281, \mathrm{~T} 3_{\text {October } 2016}=1,232, \mathrm{~T}_{\mathrm{March}}\right.$ $2017=1,176$, and T5 October $2017=931)^{1}$, was a combination of truancy (on average, 6.3 students per class were absent from school at each wave), errors in filling out the unique alphanumeric code that was used to link participants across time (about $12 \%$ of participants per study wave could not be linked), and the fact that students who attended 3-year secondary schooling programs left school between waves 4 and 5. The analytic sample for this study included 743 male students $\left(M_{\mathrm{age}}=15.9, \mathrm{SD}=0.54\right)$, of whom 186 took part in all 5 study waves. At baseline, $76.5 \%$ of recruited adolescent men were living with both parents $(42.8 \%$ reported a college-level educated mother and $36.5 \%$ a college-level educated father). In terms of religiosity, $32.1 \%$ of them reported none or very rare (once in several years) attendance of religious ceremonies, while $17.1 \%$ reported regular attendance (several times a month or more often). At baseline, about one in four participants (25.8\%) reported to have had a sexual intercourse. Finally, less than $2 \%$ of male adolescents in the sample indicated that they were mostly or exclusively attracted to persons of their own sex (the question was first asked at T3).

\footnotetext{
${ }^{1}$ The longitudinal research project included six data collection waves (the final one was carried out in March 2018). Considering that two of the four key indicators (internalization of appearance ideals and body surveillance) were not measured at T6, the final data collection wave was omitted from the current study.
} 
To address possible bias associated with attrition, multivariate logistic regression analysis was used to identify possible differences between adolescents who participated in all five study waves (coded 1) and all other participants (coded 0) in baseline socio-demographic characteristics (age, school grades, living with both parents, parents' education, and religiosity), sexual intercourse experience, and four key constructs explored in this study: the internalization of appearance ideals, body surveillance, frequency of the use of sexually explicit material, and daily use of social networking sites. Consistent with the evidence on the negative relationship between truancy and academic achievement (Balkıs, Arslan, \& Duru, 2016; Morrissey, Hutchison, \& Winsler, 2014), students who participated in all study waves reported a higher academic standing than their peers $(\mathrm{AOR}=2.33, p=.000)$, and were characterized by substantially higher odds of reporting baseline sexual activity $(\mathrm{AOR}=3.32$, $p=.000)$ and a somewhat higher frequency of pornography use $(\mathrm{AOR}=1.14, p=.011)$ than their peers who did not participate in all study waves.

\section{Procedure}

At each study wave, a classroom-based self-administered survey was distributed during a regular school class. Information needed for informed consent was presented prior to surveying by a research assistant and it was also printed on the first page of the questionnaire. To maximize confidentiality, participants were separated by $50 \times 50 \mathrm{~cm}$ portable screens. Depending on the study wave, the questionnaire included between 126 and 133 items and took 15-20 minutes to complete. No incentives were offered. In the event that participation in the survey triggered negative emotions or concerns, contact information of a youth mental health center was provided at the end of each questionnaire. All study procedures were approved by the Ethical Review Board of the Faculty of Humanities and Social Sciences, University of Zagreb.

\section{Measures}


Sexually explicit material. The frequency of the use of sexually explicit material was assessed for the period of six months before the survey using an eight-point scale ranging from $1=$ never to $8=$ several times a day. In the questionnaire, sexually explicit material was defined as "any material, which openly (i.e., not censored) depicts sexual activity. Material which shows naked bodies but not sexual intercourse or other sexual activity does not belong to pornography as here defined." Taking into account the developmental dynamics of adolescence, the indicator's stability across the five waves was satisfactory $(r=.77-.51)$.

Social networking sites. Daily use of online social networking sites was addressed by asking participants to estimate the time they spend using online social networking sites: "On average, how many hours per day do you spend on social networking sites, such as Facebook, Twitter, Instagram, etc.?" This single-item measure, which had acceptable stability during the observed period ( $r=.73-.46)$, has been frequently used in adolescent research (Doornwaard et al., 2014; Kim \& Chock, 2015; Manago et al., 2015).

The internalization of appearance ideals. Four items ("I would like my body to look like movie stars' and models' bodies"; "I compare my appearance to the appearance of celebrities"; "I would like to look like performers from the music videos"; "I would like my body to look like a professional athlete's body") from the internalization subscale of the Sociocultural Attitudes toward Appearance Questionnaire (Thompson, Van Den Berg, Roehrig, Guarda, \& Heinberg, 2004) was used to measure the internalization of appearance ideals. This shortened unidimensional composite measure had acceptable reliability in both the pilot study carried out among high-school students in a different Croatian city (Cronbach's $\alpha=.72$ ) and in this study's baseline assessment (Cronbach's $\alpha=.79$ ). Temporal stability of the construct across the five waves was satisfactory $(r=.73-.55)$. Responses were anchored on a five-point scale ranging from $1=$ strongly disagree to $5=$ strongly agree. Higher scale scores denote a higher degree of the internalization of appearance ideals. 
Body surveillance. The four-item subscale from the Objectified Body Consciousness Scale for Adolescents (Lindberg, Hyde, \& McKinley, 2006) was used to measure body surveillance. Using a five-point scale ranging from $1=$ never to $5=$ often, participants evaluated the following statements: "I often compare how I look with how other people look"; "During the day, I think about how I look many times"; "I worry about whether the clothes I am wearing make me look good"; and "I worry about how I look to other people". Responses were summed to form a composite scale that had satisfactory baseline reliability (Cronbach's $\alpha=$ $.78)$ and stability over time $(r=.75-.53)$. Higher values indicate higher body surveillance levels.

Peer popularity. The desire to be popular among peers was a composite indicator obtained by summing five items (e.g., "I have done things to make me more popular even when it meant doing something I would not usually do"; "I have been friends with some people just because others liked them") adapted from the adolescent peer popularity measure developed by Santor, Messervey, and Kusumakar (2000). The indicator had acceptable internal consistency in this study (Cronbach's $\alpha=.78$ ).

Adverse family environment. Focusing on hostile and/or aggressive family atmosphere, this indicator was assessed at baseline. Three items that asked about the frequency of intense domestic quarrels, aggressive behaviors, and family members being systematically ignored in the past 12 months were averaged to obtain a composite measure. A 5-point scale ranging from $1=$ never to $5=$ often was used to anchor answers. Taking into account the number of items and distinct facets of family behaviors addressed, the measure had acceptable internal consistency (Cronbach's $\alpha=.62$ ). Higher scores denote a more adverse family environment.

\section{Data Analysis}

Following missing data analysis, which indicated that $<1.7 \%$ of information was missing across the four key indicators (after attrition was taken into account), full information 
maximum likelihood (FIML) estimation method was employed to deal with missing information (Graham, 2012). Next, to address participants' clustering in classrooms $(n=60)$, intra-class coefficient for each of the four indicators was estimated with linear mixed effects regression modeling. Due to the fact that data nestedness was marginal (3.6\% in male adolescents' pornography use, $6.3 \%$ in the use of social networking sites, $3.8 \%$ in the internalization of appearance ideals, and 3.4\% in body surveillance was explained at the level of classroom), it was ignored in further analysis.

To address associations among the key constructs during the observed period, this study used multi-domain latent growth curve modeling (LGCM). A robust, flexible, and highpowered statistical approach to longitudinal data analysis (Curran, Obeidat, \& Losardo, 2010), LGCM enables simultaneous estimation of intra-individual (random effects) and between-individual (fixed effects) changes over time and — within a multiple-domain or parallel process framework - their relationships across latent constructs (Little, 2013; Xitao \& Xiaotao, 2005). In LGCM, each construct is represented by two factors, a latent intercept, which indicates the construct's baseline level, and a latent slope, which indicates its change over time (i.e., positive or negative growth).

LGCM was carried out incrementally. First, to identify an appropriate growth curve, a linear curve (specified in months) and an unspecified curve were fit to each of the four key constructs. The non-linear growth trajectory, which was specified by fixing the first loading to 0 and the last one to 1 , represented a cumulative growth in the observed period (Preacher, Wichman, MacCallum, \& Briggs, 2008). Based on the standard chi-square difference test for nested models, the less complex model (linear curve) was selected over the more complex one (cumulative curve) if no statistically significant $\Delta \chi^{2}$ was observed. This was the case only with body surveillance; a cumulative trajectory fit the change in the use of sexually explicit material and social networking sites, as well as the internalization of appearance ideals, 
significantly better than a linear trajectory. As recommended, error variances of manifest variables were constrained to equality (by construct) in all LGCM analyses (Duncan, Duncan, \& Strycker, 2006; Little, 2013).

To assess a multiple-domain model fit, chi-square, Tucker-Lewis or non-normed fit index (TLI), comparative fit index (CFI), and the root mean square error of approximation (RMSEA) were used (Little, 2013). Values of TLI and CFI $\geq .95$, and RMSEA $<.05$ (with the upper end of $90 \%$ confidence interval $<.08$ ) were taken to indicate good model fit (Hair, Black, Babin, \& Anderson, 2010; Schreiber, Nora, Stage, Barlow, \& King, 2006). In the final step, the model was trimmed for parsimoniousness and better visual representation by omitting non-significant paths, as long as its fit to the data remained unchanged (nonsignificant $\Delta \chi^{2}$ ). All LGCM analyses were carried out using IBM AMOS 24.0 statistical software package (Arbuckle, 2016).

\section{Results}

\section{Descriptive Statistics}

Descriptive information and cross-correlations between all assessed variables are presented in Table 1. Bivariate associations between the use of sexually explicit material and social networking sites on the one hand and the internalization of appearance ideals and body surveillance on the other hand were positive, small, and mostly significant. Expectedly, the relationships between the internalization of appearance ideals and body surveillance among male adolescents were moderate to strong and significant across time.

\section{TABLE 1 ABOUT HERE}

Figure 1 depicts mean changes in the internalization of appearance ideals and body surveillance during the observed period. At the group level, the internalization of appearance 
ideals and body surveillance had similar non-linear trajectories. Although at T1 the mean level of body surveillance was somewhat higher than the mean level of the internalization of appearance ideals, at T5 the mean levels of both constructs were almost identical and lower than at baseline. Over time and in a non-linear fashion, the use of sexually explicit material slightly increased, while the use of social networking sites slightly decreased.

\section{FIGURE 1 ABOUT HERE}

\section{Changes in Media Use, Internalization of Appearance Ideals, and Body Surveillance during the Observed Period}

Following comparative curve specifications by construct, a multiple-domain LGC model was tested (see Figure 2). The model demonstrated an acceptable fit: $\chi^{2}(173)=467.12$, $\mathrm{TLI}=.927, \mathrm{CFI}=.940, \mathrm{RMSEA}=.048[90 \% \mathrm{CI}=.043-.053]$. Significant mean growth was found only in the internalization of appearance ideals and body surveillance. In both cases, the latent growth was negative, pointing to decreasing levels of the two constructs in this panel sample of male adolescents. A significant negative association between latent intercept and latent slope was observed in each of the four constructs, which is likely related to the scaling method used (i.e., restricted measurement scale; see Little, 2013: 260). Importantly, significant individual variation was observed in all latent intercepts and slopes (see Table 2).

FIGURE 2 AND TABLE 2 ABOUT HERE

\section{Longitudinal Associations between the Key Constructs}

After non-significant paths were omitted for parsimoniousness from the full model presented in Figure 2, without affecting its fit $\left(\Delta \chi^{2}(\Delta \mathrm{df}=15)=19.63, p=.187\right)$, the trimmed 
model $\left(\chi_{(188)}^{2}=486.75, \mathrm{TLI}=.932, \mathrm{CFI}=.939, \mathrm{RMSEA}=.046[90 \% \mathrm{CI}=.041-.051]\right)$ pointed to a few significant associations between the constructs of interest. As shown in Figure 3, no substantial links between changes in the use of either social networking sites or sexually explicit material and changes in the internalization of appearance ideals and body surveillance were observed. Significant associations were found only between baseline levels of media use and body-related concerns. A more frequent use of sexually explicit material was related to male adolescents' internalization of appearance ideals $(r=.20, \mathrm{SE}=0.25, p=$ $.000)$ and body surveillance $(r=.28, \mathrm{SE}=0.20, p=.000)$. Higher baseline social networking was also substantially related to the two constructs $(r=.23, \mathrm{SE}=0.20, \mathrm{p}=.000$ and $\mathrm{r}=.23$, $\mathrm{SE}=0.16, \mathrm{p}=.000$, respectively). To compare the strength of the associations between, respectively, the use of sexually explicit material and social networking sites and baseline levels of the internalization appearance ideals and body surveillance, the fit of the model in which relevant paths were constrained to equality was compared to the non-constrained model (i.e., the trimmed model). The analysis indicated that the small but significant contributions of the use of sexually explicit material and social networking sites to the internalization of appearance ideals and body surveillance were indistinguishable by size $\left(\Delta \chi^{2}(\Delta \mathrm{df}=3)=7.01, p=\right.$ $.071)$.

FIGURE 3 ABOUT HERE

\section{Controlling for Possible Confounding of Peer Popularity and Adverse Family}

\section{Environment}

Finally, this study addressed the robustness of the findings by including the indicator of the desire to be popular among peers and the measure of adverse family environment in the trimmed model as potential confounders of the observed associations between the four 
constructs of interest. Despite the fact that baseline peer popularity scores were significantly associated with all four latent intercepts $\left(r_{\text {use of sexually explicit material }}=.21, r_{\text {use of social networking sites }}=\right.$ $.19, r_{\text {internalization }}=.40$, and $r_{b o d y}$ surveillance $=.43$, all at $\left.p=.000\right)$, the structural associations between the key constructs remained significant (all at $p=.000$ ), although somewhat attenuated. Adverse family environment was not significantly related to any of the key constructs.

\section{Discussion}

Although there is evidence suggesting that exposure to/use of objectifying content in the media triggers body surveillance in both youth and adults, most of the studies conducted so far have been cross-sectional. Furthermore, they have used exclusively female samples and have focused on the use of traditional media, such as printed magazines and television. Finally, only a few of the studies have also assessed the role of the internalization of appearance ideals in the relationship between media use and body surveillance (Karsay, Knoll, \& Matthes, 2018). Using five-wave longitudinal data, this study aimed to explore the parallel changes in the use of social networking sites and sexually explicit material, the internalization of appearance ideals, and body surveillance in men over a period of 22 months during the transition from middle to late adolescence. While this study confirmed the association between both baseline levels and changes in the internalization of appearance ideals and body surveillance, it failed to provide evidence for a longitudinal relationship between respectively the use of online social networks and sexually explicit material and either the internalization of appearance ideals or body surveillance among adolescent men.

\section{Changes in Body Surveillance during the Transition from Middle to Late Adolescence}

Over the period of 22 months, body surveillance decreased compared to the baseline level. This finding may be related to adolescent developmental processes so that in early and middle adolescence, boys may engage in more body surveillance as they experience muscle 
growth and an increase in height (Brown, Patel, \& Darmawan, 2017). Once they have reached physical maturation and approached the male body ideal, older adolescents may become less focused on their physical appearance. However, previous research shows no clear pattern of the development of body surveillance and other body concerns during the transition from adolescence to young adulthood. For example, studies conducted among younger adolescent boys found an increase in body surveillance and body dissatisfaction (Dakanalis et al., 2015; Eisenberg, Neumark-Sztainer, \& Paxton, 2006), stability in body dissatisfaction (de Vries, Peter, de Graaf, \& Nikken, 2016) or either a decrease in body dissatisfaction (Bearman et al., 2006) and disordered eating (Ferreiro, Seoane, \& Senra, 2014) or an increase in body image satisfaction (Holsen, Jones, \& Birkeland, 2012). Similarly, studies conducted among older adolescent men have shown either an increase in body surveillance, body dissatisfaction, and body shame (Bucchianeri, Arikian, Hannan, Eisenberg, \& Neumark-Sztainer, 2013; Jackson \& Chen, 2015) or have reported a decrease in body surveillance (Aubrey, 2006). While several other longitudinal studies suggested either stability (Vandenbosch \& Peter, 2016) or a slight increase (Rousseau \& Eggermont, 2018; Vangeel et al., 2018) in body surveillance during the observed period, they used mixed-age and mixed-sex samples, leaving the levels and change in body surveillance among male adolescents in their samples unclear.

Considering that the available evidence suggests that the stage of adolescent development as well as gender are important factors to consider in the assessment of the levels and change in self-objectification and the related phenomena (McCabe \& Ricciardelli, 2004), a strength of this study is the use of a single-sex age cohort (male high school students aged 16 years at baseline), which provides developmentally specific interpretations of the changes in body surveillance during the transition from middle to late adolescence.

\section{Longitudinal Relationship between the Internalization of Appearance Ideals and Body}

\section{Surveillance}


Providing support for the first hypothesis, both the internalization of appearance ideals and body surveillance had similar non-liner trajectories over the period of 22 months, and both have decreased compared to the baseline levels. Overall, this study's results are consistent with previous research in both men (Davids et al., 2018; Parent \& Moradi, 2011) and in adolescents that suggested either a cross-sectional (Vandenbosch \& Eggermont, 2013) or a longitudinal relationship (Dakanalis et al., 2015; Vandenbosch \& Eggermont, 2016) between the internalization of appearance ideals and body surveillance, with all but one of them (Rousseau \& Eggermont, 2018) reporting that this relationship is positive. Although rather than assessing the sequential order, this study considers parallel changes over time in the two constructs, it is of note that while within the framework of objectification theory, the internalization of appearance ideals is conceptualized as a predictor of body surveillance (Fredrickson \& Roberts, 1997; Moradi \& Huang, 2008), there is longitudinal evidence for both the internalization of appearance ideals predicting body surveillance (Dakanalis et al., 2015) and body surveillance predicting the internalization of appearance ideals (Rousseau \& Eggermont, 2018; Vangeel et al., 2018).

\section{Media Use, the Internalization of Appearance Ideals, and Body Surveillance}

Consistent with previous research (e.g., Doornwaard et al., 2014) and objectification theory (Fredrickson \& Roberts, 1997; Moradi \& Huang, 2008), and supporting the hypothesis that the initial levels of the use of social networking sites and sexually explicit material will be positively associated with the initial levels of the internalization of appearance ideals and body surveillance in male adolescents, this study found small but significant contributions of the use of social networking sites and sexually explicit material to both the internalization of appearance ideals and body surveillance. However, the third hypothesis was not confirmed. At baseline, the use of social networking sites and the use of sexually explicit material were characterized by comparable links to the internalization of appearance ideals and body 
surveillance. Although they did use a different analytical strategy, this finding corresponds to the comparable associations between the baseline use of social networking sites and sexually explicit material and body surveillance 18 months later reported by Doornwaard and collaborators (2014). Even so, the lack of a difference in effect sizes does not imply a similarity in engagement with the two types of media assessed in this study, given that in addition to passive consumption, the use of social networking sites includes also active content production. Finally, this study found no support for an association between changes over time in the use of social networking sites and sexually explicit material and changes in the internalization of appearance ideals and body surveillance. Similarly, Doornwaard and collaborators (2014) found that the baseline use of social networking sites and sexually explicit material were related to body surveillance 18 months later, but like this study, they failed to find an association between the increase in the use of either media during the observed period and body surveillance at the end of the study period.

Taken together, the comparable baseline associations as well as the lack of a longitudinal relationship between changes in the use of social networking sites and sexually explicit material and changes in the internalization of appearance ideals and body surveillance found in this study may suggest that appearance ideals and their internalization could potentially be more directly shaped by parental, peer and influences from traditional media that already emerge prior to the possible engagement with either social networking sites or sexually explicit material (McCabe \& Ricciardelli, 2004; Smolak, 2004). For example, previous research suggested that positive relationships reduce boys and male adolescents' risk of developing body-related concerns (McCabe \& Ricciardelli, 2004). In this context, parental and peer influences can be either direct, through appearance-related feedback or through comments prompting children and adolescents to lose weight or gain weight and muscles (de Vries et al., 2016; Xu et al., 2010), or they can be indirect and related to the general social 
environment and support (Bearman et al., 2006; de Vries et al., 2019). While weight-based comments and teasing have been shown to be associated with unhealthy weight-control behaviors and an increase in weight and fat gain (Golden, Schneider, \& Wood, 2016; Schvey et al., 2019), research suggests that greater parental and peer support are both crosssectionally and longitudinally negatively associated with weight-related concerns and behaviors and body dissatisfaction, not in the least because good social bonds are protective against the internalization of appearance ideals and social comparisons (de Vries et al., 2019; Golden et al., 2016). In the current study as well, the peer level indicator (i.e., wanting to be popular among peers) somewhat attenuated the structural associations between the four key constructs, which is aligned with previous findings suggesting that relying on others for approval or monitoring peers on social networking sites affects the relationship between media use and body-related concerns in adolescents (Vandenbosch \& Peter, 2016).

There is also some evidence suggesting that the exposure to mainstream media content may be more relevant for the development of body surveillance in adolescents than is the use of social networking sites. A recent longitudinal study reported that the association between the use of traditional media and body surveillance in adolescent men was fully mediated by the internalization of appearance ideals, whereas it found no support for a relationship between the frequency of the use of social networking sites and either the internalization of appearance ideals or body surveillance (Vandenbosch \& Eggermont, 2016). Evidence regarding the use of sexually explicit material points to gender-specific effects that differentiate between body functionality- and appearance-based objectification, of which the latter is likely more closely related to body surveillance. Specifically, a qualitative study conducted among Swedish adolescents reported that male adolescents were most influenced by body performance and function, while female adolescents were primarily influenced by the physical representations depicted in pornographic content (Löfgren-Mårtenson \& Månsson, 
2010). Therefore, although both men and women are objectified in sexually explicit material, given that the objectification of the female body in pornographic images is primarily appearance-based and the objectification of the male body is primarily body functionalitybased (Klaassen \& Peter, 2015), this study's findings do not rule out the possibility that the use of sexually explicit material may influence young men's sense of masculinity rather than their appearance-related concerns and self-objectification. Consequently, future assessments of the relationship between the use of sexually explicit material and body surveillance in men may also address preoccupation with body functionality, and not only with body appearance. Currently, however, the available cross-sectional evidence does not suggest there is an association between body functionality-related self-objectification (e.g., flexibility, endurance, and agility), which sexually explicit material promotes as desirable male characteristics (Francken, van de Wiel, van Driel, \& Weijmar Schultz, 2002; Lever, Frederick, \& Peplau, 2006), and body surveillance in men (Daniel, Bridges, \& Martens, 2014).

Finally, further investigations of the relationship between the use of social networking sites or sexually explicit material and self-objectification in men may also benefit from the inclusion of the mode of engagement with (i.e., passive consumption and active production of content) and motives for the use of social networking sites (e.g., communication with friends, group or individual identity development and expression (Ceglarek \& Ward, 2016)), and genres of sexually explicit material, as it may also be interesting to explore if and how masculine-centered narratives, compared to narratives centering on joint and/or women's pleasure (Fritz \& Paul, 2017) affect self-objectification in men. Furthermore, the inclusion of individual-level factors in future research, such as sexual orientation, may enable a more specific assessment of the role of media use in self-objectifying behavior. Previous research, for example, suggested that male bodies are more sexually idealized in gay pornography and, 
compared to heterosexual men, gay men tend to report higher levels of self-objectification (Engeln-Maddox et al., 2011; Martins, Tiggemann, \& Kirkbride, 2007) and experience antifat bias (Foster-Gimbel \& Engeln, 2016) and weight-based victimization (Puhl, Himmelstein, \& Watson, 2019) even when technically they may not be overweight.

\section{Study Strengths and Limitations}

Strengths of this study are the use of a single-sex age cohort (male high school students aged 16 years at baseline), which provides developmentally specific interpretations of this study's results, and five-wave longitudinal data, which enabled the assessment of the parallel changes in the internalization of appearance ideals and body surveillance during the transition from middle to late adolescents, as well as the inclusion of the internalizations of appearance ideals, which was hypothesized to be an important covariate in the relationship between media use and self-objectification .

Following the approach used by a number of researchers (see for example Landripet \& Štulhofer, 2015; Muusses, Kerkhof, \& Finkenauer, 2015), the frequency of the use of sexually explicit material in this study was assessed with a one-item indicator. Although this decision may be considered a limitation, it is consistent with the literature suggesting that single-item indicators should be used when the measured construct and its attributes are easily and uniformly understood (Bergkvist \& Rossiter, 2007; Diamantopoulos, Sarstedt, Fuchs, Wilczynski, \& Kaiser, 2012). A possible limitation of this study, however, is the use of a oneitem indicator of the frequency of use of social networking sites. The use of a more specific measure of engagement with social networking sites would have enabled an assessment of different aspects of the use of social networking sites, in particular given that previous research showed that the passive use of social networking sites is related to social comparisons and envy, while the active use of social networking sites is associated with 
feelings of social connectedness and greater wellbeing (Verduyn, Ybarra, Résibois, Jonides, \& Kross, 2017).

Another likely limitation is the use of general measures of the internalization of appearance ideals and body surveillance. First, the measures were developed primarily in female samples (Moradi, 2010; Vandenbosch \& Eggermont, 2013) and taking into account gender-specific cultural standards of beauty and the related pressures that young men face (Leit, Pope, \& Gray, 2001; Waling, Duncan, Angelides, \& Dowsett, 2018), the use of genderspecific measures may improve precision. Although general measures of the internalization of appearance ideals have been found useful in a number of surveys, including this one, future assessments of the construct's association with the use of social networking sites or sexually explicit material would benefit from taking into account the dominant cultural standards related to the masculine body ideals (Lanzieri \& Cook, 2013; Waling et al., 2018). Secondly, the general measures may not be sensitive enough or content-specific in the context of the use of sexually explicit material. It should be noted, however, that the use of body concerns measures that are more related to sexually explicit material would require extensive qualitative pre-assessment, due to the risk of social desirability affecting participants' answers. Cultural expectations that discourage men from displaying concern about their physical appearance may likely increase this risk (Vandenbosch \& Eggermont, 2013).

\section{Conclusion}

The growing availability and use of social networking sites and sexually explicit material prompted public concerns about the possible effects they have on different developmental outcomes. Adding to the literature on male adolescents' self-objectification, this longitudinal study provided novel insights on the relationships between adolescents' use of social networking sites and sexually explicit material, the internalization of appearance ideals and body surveillance. First, this study found that among adolescent men both the 
internalization of appearance ideals and body surveillance decreased over a period of 22 months during the transition from middle to late adolescence. Secondly, while this study confirmed the association between both baseline levels and changes in the internalization of appearance ideals and body surveillance, it failed to provide evidence for a longitudinal relationship between respectively the use of online social networks and sexually explicit material and either the internalization of appearance ideals or body surveillance among adolescent men. Therefore, this study's results offer further support for the development of targeted interventions and programs aimed at promoting body confidence among youth that involve discussions about age-specific developmental processes as well as pressures to achieve societal body ideals. Along with focusing on the role of the media, it may potentially also be beneficial to invest resources into developing positive peer and family relationships that may reduce boys and adolescent men's risk of developing body-related concerns. Finally, this study's findings highlight the potential for a more specific assessment of the role of the use of social networking sites and sexually explicit material in self-objectification and body surveillance among young men. Although this study failed to confirm a longitudinal relationship between the use of social networking sites or sexually explicit material and respectively the internalization of appearance ideals and body surveillance, future research would benefit from exploring the relationship between young men's modes of engagement with and motives for the use of social networking sites and body surveillance, as well as the potential association between the use of sexually explicit material and competency-based selfobjectification, in particular sexual body functionality. 


\section{REFERENCES}

Arbuckle, J. L. (2016). IBM AMOS 24 User's Guide. Retrieved from

ftp://public.dhe.ibm.com/software/analytics/spss/documentation/statistics/24.0/en/amos/ Manuals/IBM_SPSS_Amos_User_Guide.pdf

Attwood, F. (2005). 'Tits and ass and porn and fighting': Male heterosexuality in magazines for men. International Journal of Cultural Studies, 8(1), 83-100. https://doi.org/10.1177/1367877905050165

Aubrey, J. S. (2006). Effects of sexually objectifying media on self-objectification and body surveillance in undergraduates: Results of a 2-year panel study. Journal of Communication, 56(2), 366-386. https://doi.org/10.1111/j.1460-2466.2006.00024.x

Balkıs, M., Arslan, G., \& Duru, E. (2016). The school absenteeism among high school students: Contributing factors. Educational Sciences: Theory \& Practice, 16(6). https://doi.org/10.12738/estp.2016.6.0125

Bearman, S. K., Presnell, K., Martinez, E., \& Stice, E. (2006). The skinny on body dissatisfaction: A longitudinal study of adolescent girls and boys. Journal of Youth and Adolescence, 35(2), 217-229. https://doi.org/10.1007/s10964-005-9010-9

Bergkvist, L., \& Rossiter, J. R. (2007). The predictive validity of multiple-item versus singleitem measures of the same constructs. Journal of Marketing Research, 44(2), 175-184. https://doi.org/10.1509/jmkr.44.2.175

Brown, K. A., Patel, D. R., \& Darmawan, D. (2017). Participation in sports in relation to adolescent growth and development. Translational Pediatrics. https://doi.org/10.21037/tp.2017.04.03

Bucchianeri, M. M., Arikian, A. J., Hannan, P. J., Eisenberg, M. E., \& Neumark-Sztainer, D. (2013). Body dissatisfaction from adolescence to young adulthood: Findings from a 10year longitudinal study. Body Image, 10(1), 1-7. 
https://doi.org/10.1016/j.bodyim.2012.09.001

Calogero, R. M. (2009). Objectification processes and disordered eating in British women and men. Journal of Health Psychology, 14(3), 394-402.

https://doi.org/10.1177/1359105309102192

Ceglarek, P. J. D., \& Ward, L. M. (2016). A tool for help or harm? How associations between social networking use, social support, and mental health differ for sexual minority and heterosexual youth. Computers in Human Behavior, 65, 201-209. https://doi.org/10.1016/j.chb.2016.07.051

Chen, F. F., \& Russo, N. F. (2010). Measurement invariance and the role of body consciousness in depressive symptoms. Psychology of Women Quarterly, 34(3), 405417. https://doi.org/10.1111/j.1471-6402.2010.01585.x

Cook, I. (2006). Western heterosexual masculinity, anxiety, and Web porn. Journal of Men's Studies, 14(1), 47-63. https://doi.org/10.3149/jms.1401.47

Curran, P. J., Obeidat, K., \& Losardo, D. (2010). Twelve frequently asked questions about growth curve modeling. Journal of Cognition and Development, 11(2), 121-136. https://doi.org/10.1080/15248371003699969

Dakanalis, A., Carrà, G., Calogero, R., Fida, R., Clerici, M., Zanetti, M. A., \& Riva, G. (2015). The developmental effects of media-ideal internalization and self-objectification processes on adolescents' negative body-feelings, dietary restraint, and binge eating. European Child \& Adolescent Psychiatry, 24(8), 997-1010. https://doi.org/10.1007/s00787-014-0649-1

Daniel, S., Bridges, S. K., \& Martens, M. P. (2014). The development and validation of the Male Assessment of Self-Objectification (MASO). Psychology of Men \& Masculinity, 15(1), 78-89. https://doi.org/10.1037/a0031518

Davids, C. M., Watson, L. B., \& Gere, M. P. (2018). Objectification, masculinity, and 
muscularity: A test of objectification theory with heterosexual men. Sex Roles, 1-15. https://doi.org/10.1007/s11199-018-0940-6

de Vries, D. A., Peter, J., de Graaf, H., \& Nikken, P. (2016). Adolescents' social network site use, peer appearance-related feedback, and body dissatisfaction: Testing a mediation model. Journal of Youth and Adolescence, 45(1), 211-224. https://doi.org/10.1007/s10964-015-0266-4

de Vries, D. A., Vossen, H. G. M., \& van der Kolk - van der Boom, P. (2019). Social media and body dissatisfaction: Investigating the attenuating role of positive parent-adolescent relationships. Journal of Youth and Adolescence, 48(3), 527-536. https://doi.org/10.1007/s10964-018-0956-9

Diamantopoulos, A., Sarstedt, M., Fuchs, C., Wilczynski, P., \& Kaiser, S. (2012). Guidelines for choosing between multi-item and single-item scales for construct measurement: A predictive validity perspective. Journal of the Academy of Marketing Science, 40(3), 434-449. https://doi.org/10.1007/s11747-011-0300-3

Doornwaard, S. M., Bickham, D. S., Rich, M., Vanwesenbeeck, I., van den Eijnden, R. J. J. M., \& ter Bogt, T. F. M. (2014). Sex-related online behaviors and adolescents' body and sexual self-perceptions. Pediatrics, 134(6), 1103-1110. https://doi.org/10.1542/peds.2014-0592

Duncan, T. E., Duncan, S. C., \& Strycker, L. A. (2006). An Introduction to Latent Variable Growth Curve Modeling. An Introduction to Latent Variable Growth Curve Modeling. New York, NY: Psychology Press.

Eisenberg, M. E., Neumark-Sztainer, D., \& Paxton, S. J. (2006). Five-year change in body satisfaction among adolescents. Journal of Psychosomatic Research, 61(4), 521-527. https://doi.org/10.1016/j.jpsychores.2006.05.007

Engeln-Maddox, R., Miller, S. A., \& Doyle, D. M. (2011). Tests of objectification theory in 
gay, lesbian, and heterosexual community samples: Mixed evidence for proposed pathways. Sex Roles, 65(7), 518-532. https://doi.org/10.1007/s11199-011-9958-8

Facebook. (2019). Community Standards. Retrieved June 17, 2019, from

https://www.facebook.com/communitystandards/adult_nudity_sexual_activity/

Fasoli, F., Durante, F., Mari, S., Zogmaister, C., \& Volpato, C. (2018). Shades of sexualization: When sexualization becomes sexual objectification. Sex Roles, 78(5-6), 338-351. https://doi.org/10.1007/s11199-017-0808-1

Ferreiro, F., Seoane, G., \& Senra, C. (2014). Toward understanding the role of body dissatisfaction in the gender differences in depressive symptoms and disordered eating: A longitudinal study during adolescence. Journal of Adolescence, 37(1), 73-84. https://doi.org/10.1016/j.adolescence.2013.10.013

Foster-Gimbel, O., \& Engeln, R. (2016). Fat chance! Experiences and expectations of antifat bias in the gay male community. Psychology of Sexual Orientation and Gender Diversity, 3(1), 63-70. https://doi.org/10.1037/sgd0000159

Francken, A. ., van de Wiel, H. B. ., van Driel, M. ., \& Weijmar Schultz, W. C. . (2002). What importance do women attribute to the size of the penis? European Urology, 42(5), 426431. https://doi.org/10.1016/S0302-2838(02)00396-2

Fredrickson, B. L., \& Roberts, T.-A. (1997). Objectification theory: Toward understanding women's lived experiences and mental health risks. Psychology of Women Quarterly, 21(2), 173-206. https://doi.org/10.1111/j.1471-6402.1997.tb00108.x

Fritz, N., \& Paul, B. (2017). From orgasms to spanking: A content analysis of the agentic and objectifying sexual scripts in feminist, for women, and mainstream pornography. Sex Roles, 77(9-10), 639-652. https://doi.org/10.1007/s11199-017-0759-6

Golden, N. H., Schneider, M., \& Wood, C. (2016). Preventing obesity and eating disorders in adolescents. Pediatrics, 138(3). https://doi.org/10.1542/peds.2016-1649 
Graham, J. W. (2012). Missing Data: Analysis and Design. New York: Springer.

Hair, J. F. J., Black, W. C., Babin, B. J., \& Anderson, R. E. (2010). Multivariate Data Analysis, 7th Edition.

Holland, G., \& Tiggemann, M. (2016). A systematic review of the impact of the use of social networking sites on body image and disordered eating outcomes. Body Image, 17, 100 110. https://doi.org/10.1016/j.bodyim.2016.02.008

Holsen, I., Jones, D. C., \& Birkeland, M. S. (2012). Body image satisfaction among Norwegian adolescents and young adults: A longitudinal study of the influence of interpersonal relationships and BMI. Body Image, 9(2), 201-208. https://doi.org/10.1016/j.bodyim.2012.01.006

Jackson, T., \& Chen, H. (2015). Features of objectified body consciousness and sociocultural perspectives as risk factors for disordered eating among late-adolescent women and men. Journal of Counseling Psychology, 62(4), 741-752. https://doi.org/10.1037/cou0000096

Jackson, T., Zheng, P., \& Chen, H. (2016). Features of objectified body consciousness and sociocultural perspectives as predictors of eating and body image disturbances among young women and men in China. Journal of Gender Studies, 25(5), 599-612. https://doi.org/10.1080/09589236.2015.1073144

Karazsia, B. T., van Dulmen, M. H. M., Wong, K., \& Crowther, J. H. (2013). Thinking metatheoretically about the role of internalization in the development of body dissatisfaction and body change behaviors. Body Image, 10(4), 433-441. https://doi.org/10.1016/j.bodyim.2013.06.005

Karsay, K., Knoll, J., \& Matthes, J. (2018). Sexualizing media use and self-objectification. Psychology of Women Quarterly, 42(1), 9-28. https://doi.org/10.1177/0361684317743019

Kim, J. W., \& Chock, T. M. (2015). Body image 2.0: Associations between social grooming 
on Facebook and body image concerns. Computers in Human Behavior, 48, 331-339. https://doi.org/10.1016/j.chb.2015.01.009

Klaassen, M. J. E., \& Peter, J. (2015). Gender (in)equality in Internet pornography: A content analysis of popular pornographic Internet videos. The Journal of Sex Research, 52(7), 721-735. https://doi.org/10.1080/00224499.2014.976781

Koletić, G. (2017). Longitudinal associations between the use of sexually explicit material and adolescents' attitudes and behaviors: A narrative review of studies. Journal of Adolescence, 57, 119-133. https://doi.org/10.1016/j.adolescence.2017.04.006

Landripet, I., \& Štulhofer, A. (2015). Is pornography use associated with sexual difficulties and dysfunctions among younger heterosexual men? Journal of Sexual Medicine, 12(5). https://doi.org/10.1111/jsm.12853

Lanzieri, N., \& Cook, B. J. (2013). Examination of muscularity and body fat depictions in magazines that target heterosexual and gay men. Body Image, 10(2), 251-254. https://doi.org/10.1016/j.bodyim.2012.12.003

Leit, R. A., Pope, H. G., \& Gray, J. J. (2001). Cultural expectations of muscularity in men: The evolution of playgirl centerfolds. International Journal of Eating Disorders, 29(1), 90-93.

Lever, J., Frederick, D. A., \& Peplau, L. A. (2006). Does size matter? Men’s and women's views on penis size across the lifespan. Psychology of Men \& Masculinity, 7(3), 129143. https://doi.org/10.1037/1524-9220.7.3.129

Lindberg, S. M., Hyde, J. S., \& McKinley, N. M. (2006). A measure of objectified body consciousness for preadolescent and adolescent youth. Psychology of Women Quarterly, 30(1), 65-76. https://doi.org/10.1111/j.1471-6402.2006.00263.x

Little, T. D. (2013). Longitudinal Structural Equation Modeling. New York: Guilford Press. Löfgren-Mårtenson, L., \& Månsson, S.-A. (2010). Lust, love, and life: A qualitative study of 
Swedish adolescents' perceptions and experiences with pornography. Journal of Sex Research, 47(6), 568-579. https://doi.org/10.1080/00224490903151374

Luijkx, R., Halman, L., Sieben, I., Brislinger, E., \& Quandt, M. (2017). European Values in Numbers. Leiden: BRILL. https://doi.org/10.1163/9789004328525

Manago, A. M., Ward, L. M., Lemm, K. M., Reed, L., \& Seabrook, R. (2015). Facebook involvement, objectified body consciousness, body shame, and sexual assertiveness in college women and men. Sex Roles, 72(1-2), 1-14. https://doi.org/10.1007/s11199-0140441-1

Marinović Jerolimov, D., \& Ančić, B. (2014). Religiosity and attitudes towards sexuality and marriage of the adult population in Croatia. Društvena Istraživanja, 23(1), 111-132. https://doi.org/10.5559/di23.1.06

Marinović Jerolimov, D., \& Jokić, B. (2010). Religion and Youth in Croatia. In G. Giordan (Ed.), Annual Review of the Sociology of Religion, Volume 1: Youth and Religion. Leiden: BRILL.

Martins, Y., Tiggemann, M., \& Kirkbride, A. (2007). Those speedos become them: The role of self-objectification in gay and heterosexual men's body image. Personality and Social Psychology Bulletin, 33(5), 634-647. https://doi.org/10.1177/0146167206297403

McCabe, M. P., \& Ricciardelli, L. A. (2004). Body image dissatisfaction among males across the lifespan. Journal of Psychosomatic Research, 56(6), 675-685. https://doi.org/10.1016/S0022-3999(03)00129-6

Miner-Rubino, K., Twenge, J. M., \& Fredrickson, B. L. (2002). Trait self-objectification in women: Affective and personality correlates. Journal of Research in Personality, 36(2), 147-172. https://doi.org/10.1006/jrpe.2001.2343

Moradi, B. (2010). Addressing gender and cultural diversity in body image: Objectification theory as a framework for integrating theories and grounding research. Sex Roles, 63(1), 
138-148. https://doi.org/10.1007/s11199-010-9824-0

Moradi, B., \& Huang, Y.-P. (2008). Objectification theory and psychology of women: A decade of advances and future directions. Psychology of Women Quarterly, 32(4), 377398. https://doi.org/10.1111/j.1471-6402.2008.00452.x

Morrissey, T. W., Hutchison, L., \& Winsler, A. (2014). Family income, school attendance, and academic achievement in elementary school. Developmental Psychology, 50(3), 741-753. https://doi.org/10.1037/a0033848

Muusses, L. D., Kerkhof, P., \& Finkenauer, C. (2015). Internet pornography and relationship quality: A longitudinal study of within and between partner effects of adjustment, sexual satisfaction and sexually explicit internet material among newly-weds. Computers in Human Behavior, 45, 77-84. https://doi.org/10.1016/j.chb.2014.11.077

Parent, M. C., \& Moradi, B. (2011). His biceps become him: A test of objectification theory's application to drive for muscularity and propensity for steroid use in college men. Journal of Counseling Psychology, 58(2), 246-256. https://doi.org/10.1037/a0021398

Perloff, R. M. (2014). Social media effects on young women's body image concerns: Theoretical perspectives and an agenda for research. Sex Roles, 71(11-12), 363-377. https://doi.org/10.1007/s11199-014-0384-6

Peter, J., \& Valkenburg, P. M. (2014). Does exposure to sexually explicit Internet material increase body dissatisfaction? A longitudinal study. Computers in Human Behavior, 36, 297-307. https://doi.org/10.1016/j.chb.2014.03.071

Peter, J., \& Valkenburg, P. M. (2016). Adolescents and pornography: A review of 20 years of research. The Journal of Sex Research, 53(4-5), 509-531. https://doi.org/10.1080/00224499.2016.1143441

Preacher, K. J., Wichman, A. L., MacCallum, R. C., \& Briggs, N. E. (2008). Latent Growth Curve Modeling. Thousand Oaks, CA: Sage. 
Puhl, R. M., Himmelstein, M. S., \& Watson, R. J. (2019). Weight-based victimization among sexual and gender minority adolescents: Implications for substance use and mental health. Health Psychology, 38(8), 727-737. https://doi.org/10.1037/hea0000758

Rousseau, A., \& Eggermont, S. (2018). Media ideals and early adolescents' body image: Selective avoidance or selective exposure? Body Image, 26, 50-59. https://doi.org/10.1016/j.bodyim.2018.06.001

Rousseau, A., Eggermont, S., \& Frison, E. (2017). The reciprocal and indirect relationships between passive Facebook use, comparison on Facebook, and adolescents' body dissatisfaction. Computers in Human Behavior, 73, 336-344. https://doi.org/10.1016/j.chb.2017.03.056

Salomon, I., \& Brown, C. S. (2019). The selfie generation: Examining the relationship between social media use and early adolescent body image. The Journal of Early Adolescence, 39(4), 539-560. https://doi.org/10.1177/0272431618770809

Santor, D. A., Messervey, D., \& Kusumakar, V. (2000). Measuring peer pressure, popularity, and conformity in adolescent boys and girls: Predicting school performance, sexual attitudes, and substance abuse. Journal of Youth and Adolescence, 29(2), 163-182. https://doi.org/10.1023/A:1005152515264

Schreiber, J. B., Nora, A., Stage, F. K., Barlow, E. A., \& King, J. (2006). Reporting structural equation modeling and confirmatory factor analysis results: A review. The Journal of Educational Research, 99(6), 323-338. https://doi.org/10.3200/JOER.99.6.323-338

Schvey, N. A., Marwitz, S. E., Mi, S. J., Galescu, O. A., Broadney, M. M., Young-Hyman, D., ... Yanovski, J. A. (2019). Weight-based teasing is associated with gain in BMI and fat mass among children and adolescents at-risk for obesity: A longitudinal study. Pediatric Obesity. https://doi.org/10.1111/ijpo.12538

Smolak, L. (2004). Body image in children and adolescents: where do we go from here? Body 
Image, 1(1), 15-28. https://doi.org/10.1016/S1740-1445(03)00008-1

Štulhofer, A., Šoh, D., Jelaska, N., Baćak, V., \& Landripet, I. (2011). Religiosity and sexual risk behavior among Croatian college students, 1998-2008. Journal of Sex Research, 48(4), 360-371. https://doi.org/10.1080/00224499.2010.494257

Thompson, J. K., Van Den Berg, P., Roehrig, M., Guarda, A. S., \& Heinberg, L. J. (2004). The Sociocultural Attitudes Towards Appearance Scale-3 (SATAQ-3): Development and validation. International Journal of Eating Disorders, 35(3), 293-304. https://doi.org/10.1002/eat.10257

Tylka, T. L. (2015). No harm in looking, right? Men's pornography consumption, body image, and well-being. Psychology of Men \& Masculinity, 16(1), 97-107. https://doi.org/10.1037/a0035774

Vandenbosch, L., \& Eggermont, S. (2013). Sexualization of adolescent boys: Media exposure and boys' internalization of appearance ideals, self-objectification, and body surveillance. Men and Masculinities, 16(3), 283-306. https://doi.org/10.1177/1097184X13477866

Vandenbosch, L., \& Eggermont, S. (2016). The interrelated roles of mass media and social media in adolescents' development of an objectified self-concept. Communication Research, 43(8), 1116-1140. https://doi.org/10.1177/0093650215600488

Vandenbosch, L., \& Peter, J. (2016). Antecedents of the Initiation of Watching Sexually Explicit Internet Material: A Longitudinal Study Among Adolescents. Mass Communication and Society, 19(4), 499-521. https://doi.org/10.1080/15205436.2016.1148171

Vangeel, L., Vandenbosch, L., \& Eggermont, S. (2018). The multidimensional selfobjectification process from adolescence to emerging adulthood. Body Image, 26, 60-69. https://doi.org/10.1016/j.bodyim.2018.05.005 
Verduyn, P., Ybarra, O., Résibois, M., Jonides, J., \& Kross, E. (2017). Do social network sites enhance or undermine subjective well-being? A critical review. Social Issues and Policy Review, 11(1), 274-302. https://doi.org/10.1111/sipr.12033

Vogels, E. A. (2018). Loving oneself: The associations among sexually explicit media, body image, and perceived realism. The Journal of Sex Research, 1-13.

https://doi.org/10.1080/00224499.2018.1475546

Waling, A., Duncan, D., Angelides, S., \& Dowsett, G. W. (2018). Men and masculinity in men's magazines: A review. Sociology Compass, 12(7), e12593.

https://doi.org/10.1111/soc4.12593

Ward, L. M. (2016). Media and sexualization: State of empirical research, 1995-2015. The Journal of Sex Research, 53(4-5), 560-577. https://doi.org/10.1080/00224499.2016.1142496

Xitao, F., \& Xiaotao, F. (2005). Power of latent growth modeling for detecting linear growth: Number of measurements and comparison with other analytic approaches. The Journal of Experimental Education, 73(2), 121-139. https://doi.org/10.3200/JEXE.73.2.121-139

Xu, X., Mellor, D., Kiehne, M., Ricciardelli, L. A., McCabe, M. P., \& Xu, Y. (2010). Body dissatisfaction, engagement in body change behaviors and sociocultural influences on body image among Chinese adolescents. Body Image, 7(2), 156-164.

https://doi.org/10.1016/j.bodyim.2009.11.003 
Table 1 - Bivariate Correlations and Summary Statistics

\begin{tabular}{|c|c|c|c|c|c|c|c|c|c|c|c|c|c|c|c|c|c|c|c|c|c|c|}
\hline & 1 & 2 & 3 & 4 & 5 & 6 & 7 & 8 & 9 & 10 & 11 & 12 & 13 & 14 & 15 & 16 & 17 & 18 & 19 & 20 & M & $\mathrm{SD}$ \\
\hline 1. SEM use T1 & - & $.68 * *$ & $.62 * *$ & $.57 * *$ & $.51 * *$ & $.12 * *$ & $.20 * *$ & $.10^{*}$ & .10 & $.14^{*}$ & $.19^{* *}$ & $.13^{* *}$ & .05 & .09 & .09 & $.20^{* *}$ & $.19^{* *}$ & $.19^{* *}$ & $.13^{*}$ & $.15^{*}$ & 4.77 & 2.18 \\
\hline 2. SEM use T2 & & - & $.76^{* *}$ & $.68 * *$ & $.59 * *$ & $.13^{* *}$ & $.19 * *$ & $.14 * *$ & $.12 *$ & $.14^{*}$ & $.15^{* *}$ & $.18^{* *}$ & $.16^{* *}$ & .07 & $.17^{* *}$ & $.20 * *$ & $.26 * *$ & $.25^{* *}$ & $.17^{* *}$ & $.21 * *$ & 5.01 & 2.16 \\
\hline 3. SEM use T3 & & & - & $.76^{* *}$ & $.67 * *$ & .09 & $.17 * *$ & $.13 * *$ & .06 & $.18^{* *}$ & .10 & $.11^{*}$ & $.18^{* *}$ & $.12 *$ & .12 & $.14 * *$ & $.21 * *$ & $.22 * *$ & $.23 * *$ & $.18^{* *}$ & 4.71 & 2.17 \\
\hline 4. SEM use T4 & & & & - & $.70 * *$ & .07 & $.15^{* *}$ & .05 & $.11^{*}$ & $.21 * *$ & $.14^{* *}$ & .06 & $.16^{* *}$ & $.11^{*}$ & .11 & $.12 *$ & $.15^{* *}$ & $.19^{* *}$ & $.18^{* *}$ & $.13^{*}$ & 4.91 & 2.15 \\
\hline 5. SEM use T5 & & & & & - & $.19^{* *}$ & $.26^{* *}$ & $.22 * *$ & $.21 * *$ & $.25^{* *}$ & $.13^{*}$ & $.14^{*}$ & $.19^{* *}$ & $.15^{*}$ & $.15^{* *}$ & $.20 * *$ & $.23 * *$ & $.21 * *$ & $.21 * *$ & $.18^{* *}$ & 5.13 & 2.07 \\
\hline 6. OSN use T1 & & & & & & - & $.51 * *$ & $.46^{* *}$ & $.48^{* *}$ & $.51 * *$ & $.11 *$ & $.20 * *$ & $.12 *$ & $.11^{*}$ & $.18^{* *}$ & $.18 * *$ & $.11^{*}$ & $.13 *$ & .10 & $.21 * *$ & 2.68 & 1.89 \\
\hline 7. OSN use $\mathrm{T} 2$ & & & & & & & - & $.56^{* *}$ & $.48 * *$ & .52 & $.13^{* *}$ & $.19 * *$ & $.11^{* *}$ & $.12^{*}$ & $.17 * *$ & $.18 * *$ & $.16^{* *}$ & $.14 * *$ & $.11^{*}$ & .07 & 2.42 & 1.70 \\
\hline 8. OSN use T3 & & & & & & & & - & $.65^{* *}$ & $.70 * *$ & $.10^{* *}$ & $.16^{* *}$ & $.17^{* *}$ & $.15^{* *}$ & $.15^{*}$ & .10 & .05 & $.12 * *$ & $.11^{*}$ & $.18^{* *}$ & 2.53 & 1.69 \\
\hline 9. OSN use T4 & & & & & & & & & - & $.73 * *$ & $.16^{* *}$ & $.17^{* *}$ & $.14^{* *}$ & $.18^{* *}$ & $.15^{*}$ & $.19 * *$ & $.16^{* *}$ & $.16^{* *}$ & $.18^{* *}$ & $.24 * *$ & 2.55 & 1.74 \\
\hline 10. OSN use T5 & & & & & & & & & & - & $.14 *$ & $.17^{* *}$ & $.15^{*}$ & $.25^{* *}$ & $.23 * *$ & $.26 * *$ & $.16^{* *}$ & $.19^{* *}$ & $.22 * *$ & $.27 * *$ & 2.60 & 1.73 \\
\hline 11. Internalization $\mathrm{T} 1$ & & & & & & & & & & & - & $.67 * *$ & $.64 * *$ & $.55^{* *}$ & $.55^{* *}$ & $.49 * *$ & $.43 * *$ & $.40 * *$ & $.31 * *$ & $.32 * *$ & 9.92 & 3.92 \\
\hline 12. Internalization $\mathrm{T} 2$ & & & & & & & & & & & & - & $.72 * *$ & $.67 * *$ & $.63^{* *}$ & $.50 * *$ & $.56^{* *}$ & $.46^{* *}$ & $.42 * *$ & $.43^{* *}$ & 9.40 & 4.07 \\
\hline
\end{tabular}


13. Internalization $\mathrm{T} 3$

14. Internalization $\mathrm{T} 4$

15. Internalization $\mathrm{T} 5$

16. Body surveillance T1

17. Body surveillance $\mathrm{T} 2$

18. Body surveillance T3

19. Body surveillance T4

20. Body surveillance T5
- $\quad .66^{* *} .66^{* *} .37 * * .48 * * .52 * * .45 * * \quad .47 * * \quad 9.45 \quad 3.69$

$-.73 * * .43 * * .48 * * \quad .51 * * \quad .54 * * .46 * * \quad 9.05 \quad 3.87$

$-.39 * * .42 * * .51 * * \quad .50 * * .52 * * \quad 9.73 \quad 3.84$

$-.71 * * .60 * * .57 * * .53 * * 10.23 \quad 3.00$

$-\quad .68^{* *} .65^{* *} .54 * * \quad 9.43 \quad 3.17$

$-\quad .73 * * .67 * * \quad 9.82 \quad 2.94$

$-\quad .75^{* *} \quad 9.34 \quad 3.12$

SEM = sexually explicit material; OSN = online social networking sites; internalization = internalization of appearance ideals;

$* \mathrm{p}<.05, * * \mathrm{p}<.01$ 
Table 2 - Latent Growth Model Fit Indices and the Key Parameters

\begin{tabular}{|c|c|c|}
\hline & $\begin{array}{l}\text { Initial multiple- } \\
\text { domain model }\end{array}$ & $\begin{array}{c}\text { Trimmed } \\
\text { conditional model }\end{array}$ \\
\hline \multicolumn{3}{|l|}{ Model fit } \\
\hline$\chi^{2}(\mathrm{df})$ & $467.12(173)$ & $486.75(188)$ \\
\hline TLI / CFI & $.927 / .940$ & $.932 / .939$ \\
\hline RMSEA $(90 \% \mathrm{CI})$ & $.048(.043-.053)$ & $.046(.041-.051)$ \\
\hline
\end{tabular}

Baseline SEM use

$$
\begin{array}{lll}
\text { M (S.E.) } & 4.76(0.09)^{* *} & 4.76(0.09)^{* *} \\
\sigma^{2} \text { (S.E.) } & 3.89(0.30)^{* *} & 3.87(0.29)^{* *}
\end{array}
$$

Change in SEM use

$$
\begin{array}{lcc}
\text { M (S.E.) } & 0.17(0.10) & 0.17(0.10) \\
\sigma^{2} \text { (S.E.) } & 2.55(0.41)^{* *} & 2.54(0.41)^{* *}
\end{array}
$$

Baseline OSN use

$$
\begin{array}{lll}
\text { M (S.E.) } & 2.60(0.08)^{* *} & 2.61(0.08)^{* *} \\
\sigma^{2}(\text { S.E. }) & 2.39(0.21)^{* *} & 2.46(0.21)^{* *}
\end{array}
$$

Change in OSN use

$$
\begin{array}{lll}
\text { M (S.E.) } & -0.03(0.08) & -0.05(0.08) \\
\sigma^{2} \text { (S.E.) } & 1.50(0.29)^{* *} & 1.45(0.29)^{* *}
\end{array}
$$

Baseline internalization

$$
\begin{array}{lll}
\text { M (S.E.) } & 9.81(0.16)^{* *} & 9.81(0.16)^{* *} \\
\sigma^{2} \text { (S.E.) } & 11.80(0.93)^{* *} & 11.74(0.91)^{* *}
\end{array}
$$


Change in internalization

$$
\begin{array}{lll}
\mathrm{M}(\mathrm{S} . \mathrm{E} .) & -0.58(0.15)^{* *} & -0.59(0.16)^{* *} \\
\sigma^{2}(\mathrm{~S} . \mathrm{E} .) & 5.14(1.06)^{* *} & 5.21(1.07)^{* *}
\end{array}
$$

Baseline body surveillance

$$
\begin{array}{lll}
\text { M (S.E.) } & 9.93(0.12)^{* *} & 9.93(0.12)^{* *} \\
\sigma^{2} \text { (S.E.) } & 6.79(0.50)^{* *} & 6.77(0.49)^{* *}
\end{array}
$$

Change in body surveillance

$$
\begin{array}{lll}
\mathrm{M}(\mathrm{S} . \mathrm{E} .) & -0.03(0.01)^{* *} & -0.03(0.01)^{* *} \\
\sigma^{2} \text { (S.E.) } & 0.01(0.00)^{* *} & 0.01(0.00)^{* *}
\end{array}
$$

$\overline{\mathrm{SEM}}=$ sexually explicit material; OSN $=$ online social networking sites; internalization $=$ internalization of appearance ideals;

$* \mathrm{p}<.01, * * \mathrm{p}<.001$ 
Figure 1 - Changes in the Internalization of Appearance Ideals and Body Surveillance in Male Croatian Adolescents $(n=743)$ over a Period of 20 Months

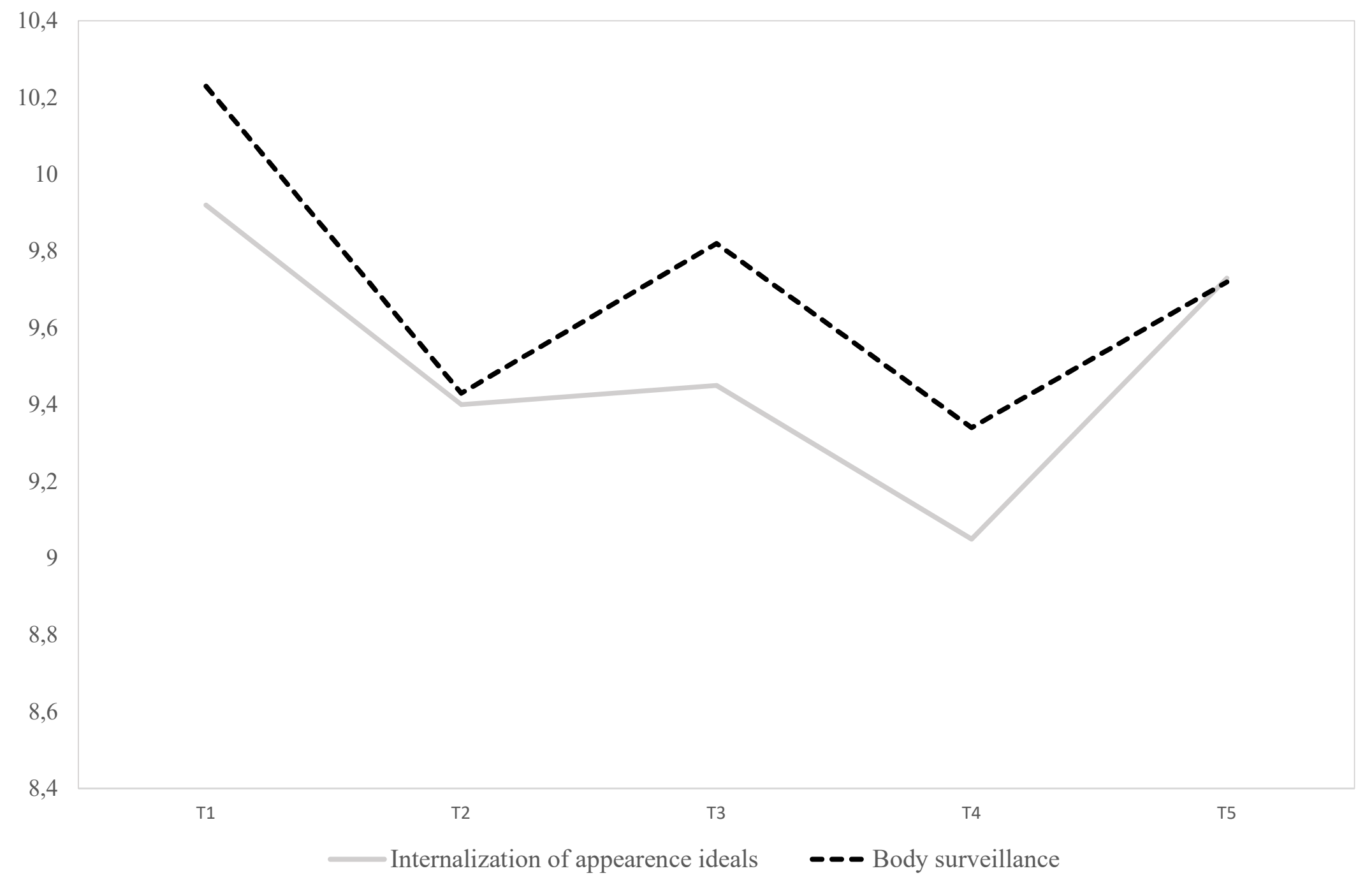


Figure 2 - Multiple-Domain Latent Growth Curve Model of Associations between SEM and OSN Use, Internalization of Appearance Ideas and Body Surveillance in Male Adolescents

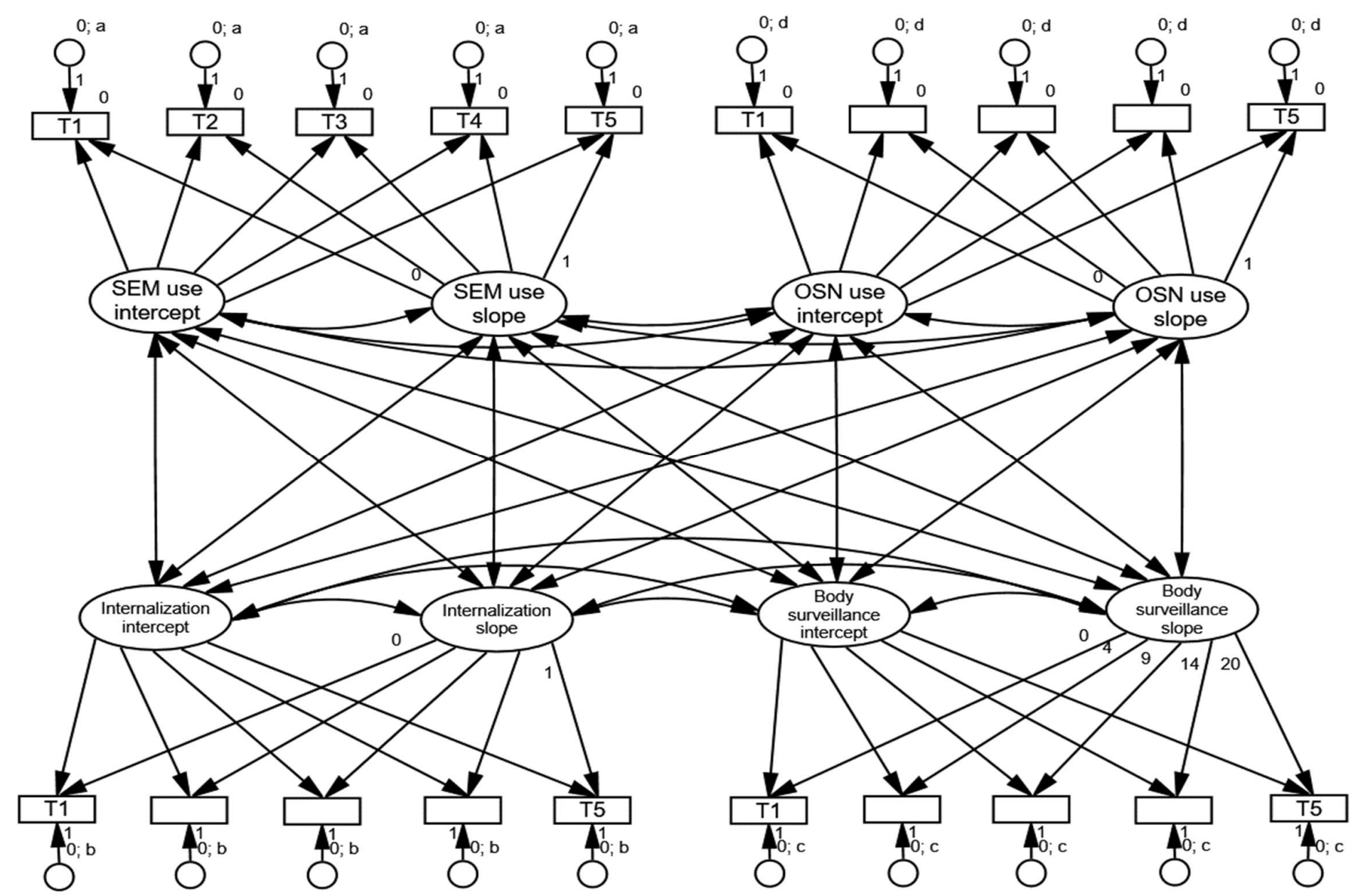

SEM = sexually explicit material; OSN = online social networking sites; internalization = internalization of appearance ideals 
Figure 3 - Final (Trimmed) Multiple-Domain Latent Growth Curve Model of the Associations between SEM and OSN Use, Internalization of Appearance Ideas and Body Surveillance in Male Adolescents

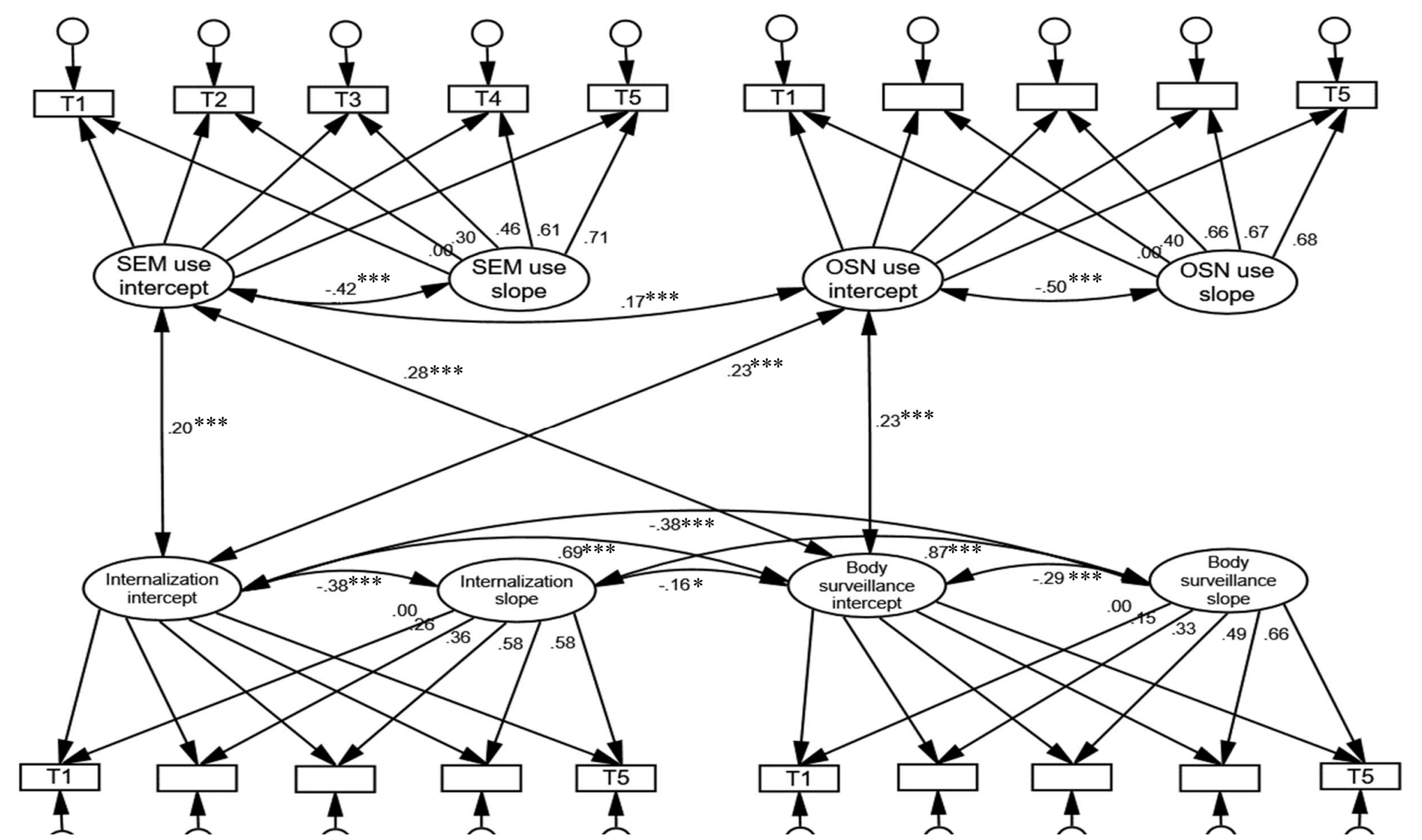

$\mathrm{SEM}=$ sexually explicit material; OSN = online social networking sites; internalization = internalization of appearance ideals; model fit: $\chi^{2}{ }_{(188)}=486.75, \mathrm{TLI}=.932, \mathrm{CFI}=.939, \mathrm{RMSEA}=.046[90 \% \mathrm{CI}=.041-.051] ;{ }^{*} p<.05,{ }^{* *} p<.01,{ }^{* * *} p<.001$ 